\title{
Fluoretação da água dos dez maiores municípios do estado do Tocantins, Brasil
}

\author{
Water fluoridation in the ten largest municipalities of the state of \\ Tocantins, Brazil
}

Ana Paula Alves Gonçalves Lacerda (https://orcid.org/0000-0001-5050-351X) ${ }^{1}$

Neilton Araujo de Oliveira (https://orcid.org/0000-0002-8976-7237) ${ }^{2}$

Helder Henrique Costa Pinheiro (https://orcid.org/0000-0001-5567-3550) ${ }^{3}$

Karina Maschietto de Lima Assis (https://orcid.org/0000-0002-8037-2386) ${ }^{4}$

Jaime Aparecido Cury (https://orcid.org/0000-0003-1046-5605) ${ }^{5}$
${ }^{1}$ Saúde Coletiva, Faculdade Presidente Antonio Carlos. 508 norte, Alameda 5 Lote 2, QI4. 77006-658

Palmas TO Brasil. apaglacerda@hotmail.com ${ }^{2}$ Universidade Federal do

Tocantins. Palmas TO

Brasil.

${ }^{3}$ Faculdade de Odontologia, Universidade Federal do

Pará. Belém PA Brasil.

${ }^{4}$ Grupo condutor de

Odontologia, Secretaria

Municipal de Saúde de

Palmas. Palmas TO Brasil.

${ }^{5}$ Faculdade de Odontologia de Piracicaba, Universidade

Estadual de Campinas.

Campinas SP Brasil.

\begin{abstract}
Water fluoridation is a strategy for caries control recommended by the WHO. In Brazil, it is regulated by law but this program has not been successfully implemented in the North region. This research aimed to collect data on the existence of external control (heterocontrol) in the ten largest municipalities in the state of Tocantins, Brazil, and to analyze fluoride concentration in the public water supply of these cities. The study was conducted from May-August $/ 17$, and its theoretical-methodological framework was a quantitative, descriptive and cross-sectional analysis. Water collections were carried out monthly, using sampling protocol of water collection of the network. Fluoride concentration in the waters was determined with ion specific electrode by the direct technique. It was verified that water fluoridation monitoring is only been done in Palmas, capital of the state, starting in 2016. Thirty-two percent of waters samples analyzed showed fluoride concentration to obtain the maximum benefit of reduction caries and $27.5 \%$ of them presented a high or very high risk of dental fluorosis. It is necessary to implement a program to control the concentration of fluoride in the water of the $m u$ nicipalities of Tocantins, in order to ensure that the population is not deprived of the anticaries' benefits of the adjustment of fluoride concentration of the treated water.
\end{abstract}

Key words Fluoridation, Surveillance, Fluorine, Water analysis
Resumo Fluoretação da água é uma estratégia de controle da cárie, recomendada pela OMS. No Brasil ela é regulamentada por lei, mas não tem sido implementada com sucesso na região Norte. Os objetivos desta pesquisa foram levantar dados sobre a existência do heterocontrole nos 10 maiores municípios tocantinenses e analisar a concentração de fluoreto presente na água de abastecimento público destas cidades. A pesquisa foi realizada de maio-agosto/17 e teve como marco teórico-metodológico a análise quantitativa, descritiva e transversal. Coletas de água foram realizadas mensalmente, utilizando protocolo de amostragem de coleta de água da rede. A concentração de fluoreto nas águas foi feita com eletrodo íon específico pela técnica direta. Constatou-se que a vigilância da fluoretação da água está em operação na capital do estado desde 2016. Com relação a concentração de fluoreto na água, foi encontrado que 31,6\% das amostras analisadas estavam adequadas para o máximo benefício de redução de cárie e 27,5\% delas apresentavam risco alto ou muito alto de fluorose dentária. É necessário implementar um programa de controle da concentração de flúor na água no Tocantins, a fim de garantir que a população não seja privada dos benefícios anticárie da agregação de flúor à agua tratada.

Palavras-chave Fluoretação, Vigilância, Flúor, Análise da água 


\section{Introdução}

O acesso à água tratada e fluoretada é essencial para o estabelecimento de condições amplas de saúde da população. Sendo de grande importância a concretização de políticas públicas que garantam a implantação, monitoramento e avaliação da fluoretação das águas de consumo ${ }^{1}$.

A fluoretação é imprescindível para a promoção da saúde, sendo uma tecnologia de intervenção em saúde pública eficaz e recomendada pela Organização Mundial de Saúde (OMS), que a considera como uma forma indispensável nas estratégias preventivas em saúde bucal ${ }^{2}$.

Segundo o Centers for Disease Control and Prevention (CDC) dos EUA, a água fluoretada é uma das dez grandes conquistas da saúde pública do século XX, pois previne de $40 \%$ a $70 \%$ das cáries em crianças e reduz a perda dentária em adultos de $40 \%$ a $60 \%$, sendo um método abrangente, barato, que beneficia todos os grupos sociais ${ }^{3}$.

Segundo Frazão et al. ${ }^{4}$, o acesso à água fluoretada é o método mais eficaz, eficiente, barato e recomendado para prevenção de cárie, além de integrar uma das diretrizes da Política Nacional de Saúde Bucal (PNSB), que diz respeito à atuação e consolidação da vigilância em saúde, e segundo o Ministério da Saúde mais de 100 milhões de pessoas em todo o país são beneficiadas pela medida ${ }^{5}$.

No Brasil, a fluoretação da água de abastecimento público tornou-se obrigatória através da Lei Federal no 6.050, de 24 de maio de $1974^{6}$, regulamentada pelo Decreto no 76.872 , de 22 de dezembro de $1975^{7}$, tendo seus valores determinados pela Portaria no 635 , de 26 de dezembro de $1975^{8}$, com valores oscilando entre $0,6 \mathrm{ppm}$ a 0,8 ppm em todo o território nacional.

Embora a fluoretação tenha se tornado obrigatória, o Ministério da Saúde admite uma cobertura por volta de $60 \%$ com desigualdades entre regiões. No Sul e Sudeste, mais de 70\% das pessoas são beneficiadas pela fluoretação enquanto na região Norte, menos de $30 \%{ }^{5}$.

Segundo Frazão et al. ${ }^{9}$, dos 139 municípios tocantinenses, apenas 5 informam e alimentam regularmente o Sisagua, sendo que 127 não estão cadastrados e outros 7 estão cadastrados, mas não informam dados regularmente, sendo assim, esses sistemas são subalimentados pelos municípios e por isso existe a necessidade de fazer um controle adicional por parte das instituições estaduais, municipais ou privadas, sempre que algum produto apresentar riscos à saúde da po- pulação, além da implementação de um sistema de informação confiável e completo.

A efetividade da Fluoretação da água em capitais brasileiras no início do século XXI foi avaliada ${ }^{10} \mathrm{e}$ verificou-se que nas cidades pesquisadas houve diferença estatisticamente significativa, havendo um declínio na média CPOD nas localidades que possuem água fluoretada, porém, Palmas não foi objeto da pesquisa. Em 2010 o SB Brasil fez um levantamento epidemiológico no país, e o CPOD aos 12 anos encontrado na capital do estado do Tocantins foi de 2,83. Este valor está de acordo com o preconizado pela OMS, de que a partir de 2000 em todo o mundo, o valor médio deve ser menor do que 3 aos 12 anos $^{11}$.

A disponibilidade de água tratada fluoretada tem aumentado no Brasil produzindo benefícios para a saúde e, ao mesmo tempo, contribuindo para a redução de desigualdades. Foi o que demonstraram Frazão e Narvai ${ }^{12}$, ao avaliarem a cobertura da fluoretação da água de abastecimento público em municípios brasileiros, segundo porte demográfico e nível de desenvolvimento humano municipal (IDH-M). Mostraram que, entre 2000 e 2008, 8,6\% da população brasileira passou a receber o benefício, elevando-se a taxa de cobertura de $67,7 \%$ para $76,3 \%$, uma das mais altas coberturas entre os 10 países mais populosos do planeta. Contudo, esse crescimento foi mais acentuado nas regiões Sul, Sudeste e Centro-Oeste, ficando as regiões Norte e Nordeste com um crescimento mais discreto, lento e descoordenado.

Nos últimos anos foi relatado um aumento positivo em relação a exposição da população às diversas fontes de flúor, tais como dentifrícios, alimentos, medicações, bochechos e água de abastecimento público, este flúor pode ter um papel essencial na prevenção e controle das cáries dentárias em crianças e adultos. No entanto, dependendo da dose e do tempo de exposição exatos pode ocasionar intoxicação crônica, sendo a fluorose dentária o efeito tóxico mais comum causado pelo flúor. A sua prevalência tem se manifestado principalmente nas formas leve e muito leve, sendo observada em comunidades com água fluoretada ${ }^{13-15}$.

Vários estudos alertam para a grande variação dos níveis de fluoreto nas águas de abastecimento público e reforçam a necessidade de implantação de sistemas de vigilância eficazes e contínuos $^{14,16-18}$.

Os objetivos desta pesquisa foram levantar dados sobre a existência do heterocontrole nos 10 maiores municípios do estado do Tocantins, analisar a concentração de fluoreto presente na 


\section{Metodologia}

O presente estudo tem como marco teórico-metodológico a análise quantitativa, descritiva $\mathrm{e}$ transversal. Trata-se de uma pesquisa de campo, onde foram realizadas visitas nas estações de tratamento de água (ETA), coletas e análise, em que o foco foi conhecer a situação atual da fluoretação, a existência e eficácia do heterocontrole realizado pelas autoridades competentes em relação à qualidade e quantidade de fluoretos utilizados nestas cidades e verificar a constância dos valores do íon flúor na água fornecida à população, por isso foram realizadas coletas em três meses distintos.

$\mathrm{O}$ trabalho foi realizado nas cidades de: Palmas, Araguaína, Gurupi, Porto Nacional, Paraiso do Tocantins, Araguatins, Colinas, Guaraí, Tocantinópolis e Dianópolis.

Inicialmente foi visitada a companhia de abastecimento público do estado, denominada BRK Ambiental para capitação de informações específicas sobre a forma como é realizada a fluoretação, e também foram aplicados 2 questionários à Secretaria Estadual de Saúde do Tocantins, sendo o primeiro questionário realizado em 2014 e o segundo em 2017, com a finalidade de conhecer alguns dos aspectos do processo de fluoretação e evidenciar a atual situação e as mudanças ocorridas no sistema de abastecimento nestes 3 anos. Os questionários disponibilizaram dados que não estavam disponíveis em sites ou publicações, uma vez que não foram encontrados outros trabalhos relacionados a este assunto no Tocantins.

Para a escolha dos pontos de coleta das amostras foram respeitados os mesmos locais onde os agentes do Programa de vigilância da água do estado realizam mensalmente as coletas para análise de cor aparente, turbidez, coliformes totais, cloro residual livre e a presença ou não de Escherichia coli., levando em consideração a divisão da zona urbana dos municípios e a quantidade de ETA que cada uma das localidades pesquisadas possuem.

As amostras foram coletadas diretamente da torneira acoplada ao hidrômetro, sendo prefe-

rencialmente em locais públicos como escolas, creches e hospitais e acondicionadas em frascos de polietileno com tampa devidamente identificados.

Todas as coletas foram executadas pela Secretaria estadual e/ou municipal de Saúde presente nos 10 municípios, entre os meses de maio a agosto de 2017, pelo agente de vigilância ambiental responsável por cada localidade pesquisada. Foram respeitadas as normas e padrões estabelecidos pelo Manual de Coleta para Análises de Água de Consumo Humano do estado do Tocantins ${ }^{19}$ e pela Diretriz Nacional do Plano de Amostragem da Vigilância da Qualidade da Água para Consumo Humano do Ministério da Saúde ${ }^{20}$, seguindo os mesmos parâmetros para cloro, turbidez e coliformes, cuidando para que nenhuma região ficasse excluída das análises.

Foi utilizado um roteiro para a realização do monitoramento da qualidade da água com os seguintes passos: elaboração de plano de amostragem, com os parâmetros a serem monitorados, frequência de coleta e número de amostras a serem analisadas; definição de cronograma de encaminhamento das amostras ao laboratório de saúde pública, de acordo com a capacidade instalada no laboratório estadual, selecionado para envio das amostras; seleção dos pontos de coleta (endereços de coleta) e preenchimento das fichas de solicitação de análise no sistema de gerenciamento de ambiente laboratorial (GAL).

Finalizada a parte de planejamento, seguiu-se com a parte das coletas de água nos municípios selecionados, sendo o agente Vigiagua municipal o responsável pela execução dos passos a seguir: identificação do local para coleta da água; verificação da existência de torneira junto ao cavalete; abertura da torneira por três minutos, ou o tempo suficiente para eliminar a água estagnada na tubulação, tendo certeza de que a água seja proveniente da rede de distribuição e não de caixas ou reservatórios internos; calçamento das luvas de procedimentos para efetuar as coletas; lavagem do frasco por três vezes com a água a ser coletada; enchimento do frasco com a água, desprezando uma pequena porção da amostra, ficando um espaço vazio para permitir uma boa homogeneização antes do início da análise; identificação dos frascos e preenchimento da ficha de solicitação incluindo os dados medidos em campo e o horário do início do procedimento da coleta.

No total, 516 amostras foram coletadas de acordo com as diretrizes para amostragem de água do Vigiflúor ${ }^{21}$. Os lugares escolhidos leva- 
ram em consideração a quantidade de ETAS existentes, sendo assim, foram realizadas em vários pontos das cidades. Isso justificou a diferença entre o número de amostras, pois algumas cidades possuem apenas uma ETA, como Porto Nacional (12 coletas mensais/totalizando 36), Colinas do Tocantins (18/54), Guaraí (17/51), Dianópolis (12/36), Araguatins (14/42), Paraíso do Tocantins (10/30) e Gurupi (13/39). Enquanto outras como Palmas (18/54), Araguaína (40/120) e Tocantinópolis (18/54) tiveram um número maior de amostras pois possuem várias ETAS.

As amostras de água foram enviadas para o laboratório de Bioquímica da Faculdade de Odontologia de Piracicaba da Universidade Estadual de Campinas (Unicamp), onde foram analisadas com eletrodo específico para fluoreto pela técnica direta, usando metodologia validada. Detalhes da metodologia analítica estão descritas em publicação do projeto Vigiflúor ${ }^{22}$.

Em seguida, foi realizada uma análise descritiva envolvendo cálculos e tabelas para melhor visualização dos resultados. Foram estabelecidos dois parâmetros para critério dos valores, sendo o primeiro, o documento precursor da normatização de concentração de flúor, a Portaria GM/MS no $635 / 1975^{8}$, que aprova as normas e padrões, sobre a fluoretação da água dos sistemas públicos de abastecimento, destinada ao consumo humano, estabelecendo limites recomendados para a concentração do íon fluoreto em função da média das temperaturas máximas diárias em todo o Brasil, onde a concentração ótima de flúor para os municípios pesquisados é de $0,7 \mathrm{mg}$ F/L (ppm $\mathrm{F}$ ), podendo variar entre 0,6 e $0,8 \mathrm{mg} \mathrm{F} / \mathrm{L}$ para cidades com temperaturas compreendidas entre $26,4^{\circ} \mathrm{C}$ e $32,5^{\circ} \mathrm{C}$. O segundo parâmetro utilizado foi o Consenso Técnico brasileiro de fluoretação ${ }^{23}$, que leva em consideração a temperatura local e admite que entre $26,3^{\circ} \mathrm{C}$ e $32,5^{\circ} \mathrm{C}$, a variação ótima de flúor varia de $0,55 \mathrm{mgF} / \mathrm{L}$ a $0,84 \mathrm{mgF} / \mathrm{L}$, atribuindo máximo benefício de prevenção a cárie dentária e risco mínimo de desenvolver fluorose dentária.

Também foram realizados dois debates interdisciplinares e multidisciplinares, denominados $1^{\circ}$ e 2o Simpósio de Fluoretação ITPAC PORTO NACIONAL, sendo o primeiro em outubro de 2016 e o segundo em outubro de 2017 , com o intuito de discutir a fluoretação da água de abastecimento público, suas características e consequências.

\section{Resultados}

A partir das análises realizadas pode-se observar que a concentração média de flúor apresentou grande variação nas dez cidades pesquisadas (Tabela 1), apresentando como valor mínimo 0,03 ppm (baixa fluoretação) e valor máximo 1,07 ppm (alta fluoretação).

Também foi observado, na Tabela 1, que não houve continuidade da concentração do íon fluoreto nas amostras de água, pois na cidade de Colinas do Tocantins houve um desvio padrão de 0,40, variando desde 1,07 ppm a 0,83 ppm, seguido por Tocantinópolis que oscilou de 0,31 ppm a 0,46 ppm, Paraíso do Tocantins variou de $0,91 \mathrm{ppm}$ a $0,84 \mathrm{ppm}$, Porto Nacional alternando valores de 0,68 ppm a 0,91 ppm e por último a cidade de Dianópolis contendo variação de flúor entre 0,07 ppm e 0,77 ppm.

Observa-se na Tabela 2 os seguintes parâmetros: insignificante quando não possui proteção anticárie, mínimo quando a proteção existe, porém, é inexpressiva, benefício máximo quando a proteção a cárie é eficaz e ideal, moderado quando existe a proteção, mas também o risco de causar fluorose e malefício quando a concentração de flúor é tão elevada que o risco de agravos supera os benefícios de proteção a cárie.

$\mathrm{Na}$ Tabela 2 é possível verificar que a cidade de Araguatins teve $100 \%$ das coletas com proteção insignificante a cárie dentária, Araguaína na segunda colocação com $70,8 \%$ das amostras sem proteção, ambas com índice de flúor quase nulos, seguida de Tocantinópolis que apresentou 59,3\% das amostras sem cumprir seu papel anticárie.

Das 516 amostras analisadas, apenas 31,6\% cumpriram o papel da principal indicação do uso dos fluoretos, com benefício máximo anticárie, porém as outras $68,4 \%$ apresentaram valores abaixo ou nulos em relação a esse benefício. Também é demonstrado na Tabela 2 que as cidades como Dianópolis $(58,3 \%)$ e Guaraí $(68,6 \%)$ estão com cobertura acima de $50 \%$ das amostras em relação a prevenção da cárie dentária.

No que diz respeito ao risco de produzir fluorose, a Tabela 3 também utiliza cinco parâmetros, porém, eles são diferentes dos utilizados para classificar os benefícios de proteção a cárie dentária, pois estão de acordo com o Consenso Técnico brasileiro de fluoretação ${ }^{23}$, sendo os parâmetros da fluorose os seguintes: insignificante para o risco ausente de causar fluorose dentária, baixo para uma pequena possibilidade de desenvolver fluorose em grau questionável, moderado para uma quantidade de fluoreto capaz de produzir fluorose 
Tabela 1. Valores de concentração de fluoretos nas amostras de água de abastecimento público segundo município e período de coleta. Tocantins, 2017.

\begin{tabular}{|c|c|c|c|c|}
\hline Município & Coleta & $\mathbf{N}$ & Média & Desvio-padrão \\
\hline \multirow[t]{4}{*}{ Araguaína } & $1^{\circ}$ mês & 40 & 0,14 & 0,21 \\
\hline & $2^{\circ}$ mês & 40 & 0,25 & 0,25 \\
\hline & $3^{\circ}$ mês & 40 & 0,33 & 0,30 \\
\hline & Município & 120 & 0,24 & 0,27 \\
\hline \multirow[t]{4}{*}{ Araguatins } & $1^{\circ}$ mês & 14 & 0,05 & 0,01 \\
\hline & $2^{\circ}$ mês & 14 & 0,04 & 0,00 \\
\hline & $3^{\circ}$ mês & 14 & ${ }^{*} 0,03$ & 0,00 \\
\hline & Município & 42 & 0,04 & 0,01 \\
\hline \multirow[t]{4}{*}{ Colinas } & $1^{\circ}$ mês & 18 & ${ }^{* *} 1,07$ & 0,47 \\
\hline & $2^{\circ}$ mês & 18 & 0,83 & 0,41 \\
\hline & $3^{\circ}$ mês & 18 & 1,05 & 0,26 \\
\hline & Município & 54 & 0,98 & 0,40 \\
\hline \multirow[t]{4}{*}{ Dianópolis } & $1^{\circ}$ mês & 12 & 0,17 & 0,01 \\
\hline & $2^{\circ}$ mês & 12 & 0,44 & 0,23 \\
\hline & $3^{\circ}$ mês & 12 & 0,77 & 0,04 \\
\hline & Município & 36 & 0,46 & 0,28 \\
\hline \multirow[t]{4}{*}{ Guaraí } & $1^{\circ}$ mês & 17 & 0,42 & 0,15 \\
\hline & $2^{\circ}$ mês & 17 & 0,55 & 0,23 \\
\hline & $3^{\circ}$ mês & 17 & 0,63 & 0,09 \\
\hline & Município & 51 & 0,54 & 0,18 \\
\hline \multirow[t]{4}{*}{ Gurupi } & $1^{\circ}$ mês & 13 & 0,86 & 0,09 \\
\hline & $2^{\circ}$ mês & 13 & 0,87 & 0,04 \\
\hline & $3^{\circ}$ mês & 13 & 0,80 & 0,03 \\
\hline & Município & 39 & 0,84 & 0,07 \\
\hline \multirow[t]{4}{*}{ Palmas } & $1^{\circ}$ mês & 18 & 0,77 & 0,27 \\
\hline & $2^{\circ}$ mês & 18 & 0,83 & 0,19 \\
\hline & $3^{\circ}$ mês & 18 & 0,75 & 0,25 \\
\hline & Município & 54 & 0,78 & 0,24 \\
\hline \multirow[t]{4}{*}{ Paraíso } & $1^{\circ}$ mês & 10 & 0,91 & 0,19 \\
\hline & $2^{\circ}$ mês & 10 & 0,85 & 0,37 \\
\hline & $3^{\circ}$ mês & 10 & 0,84 & 0,32 \\
\hline & Município & 30 & 0,86 & 0,29 \\
\hline \multirow[t]{4}{*}{ Porto Nacional } & $1^{\circ}$ mês & 12 & 0,91 & 0,12 \\
\hline & $2^{\circ}$ mês & 12 & 0,68 & 0,39 \\
\hline & $3^{\circ}$ mês & 12 & 0,95 & 0,06 \\
\hline & Município & 36 & 0,85 & 0,26 \\
\hline \multirow[t]{4}{*}{ Tocantinópolis } & $1^{\circ}$ mês & 18 & 0,31 & 0,31 \\
\hline & $2^{\circ}$ mês & 18 & 0,36 & 0,29 \\
\hline & $3^{\circ}$ mês & 18 & 0,46 & 0,29 \\
\hline & Município & 54 & 0,38 & 0,30 \\
\hline \multirow[t]{3}{*}{ Total } & $1^{\circ}$ mês & 172 & 0,49 & 0,43 \\
\hline & $2^{\circ}$ mês & 172 & 0,52 & 0,38 \\
\hline & $3^{\circ}$ mês & 172 & 0,61 & 0,37 \\
\hline Total & & 516 & 0,54 & 0,40 \\
\hline
\end{tabular}

muito leve e leve, risco alto onde a concentração do íon causaria fluorose moderada, e risco muito alto podendo desencadear fluorose severa.
Na Tabela 3 também é verificada uma situação preocupante, Colinas possui $77,8 \%$ das amostras com risco alto de produzir fluorose 
Tabela 2. Frequências absolutas e relativas das classificações do benefício na prevenção da cárie das amostras de água de abastecimento público segundo município. Tocantins, 2017.

\begin{tabular}{|c|c|c|c|c|c|c|c|c|c|c|c|c|}
\hline \multirow{3}{*}{ Município } & \multicolumn{12}{|c|}{ Benefício } \\
\hline & \multicolumn{2}{|c|}{ Insignificante } & \multicolumn{2}{|c|}{ Mínimo } & \multicolumn{2}{|c|}{ Máximo } & \multicolumn{2}{|c|}{ Moderado } & \multicolumn{2}{|c|}{ Malefício } & \multicolumn{2}{|c|}{ Total } \\
\hline & $\mathrm{N}$ & $\%$ & $\mathbf{N}$ & $\%$ & $\mathbf{N}$ & $\%$ & $\mathbf{N}$ & $\%$ & $\mathbf{N}$ & $\%$ & $\mathbf{N}$ & $\%$ \\
\hline Araguaína & 85 & 70,8 & 2 & 1,7 & 31 & 25,8 & 1 & 0,8 & 1 & 0,8 & 120 & 100,0 \\
\hline Araguatins & 42 & 100 & 0 & 0,0 & 0 & 0,0 & 0 & 0,0 & 0 & 0,0 & 42 & 100,0 \\
\hline Colinas & 7 & 13,0 & 0 & 0,0 & 4 & 7,4 & 42 & 77,8 & 1 & 1,9 & 54 & 100,0 \\
\hline Dianópolis & 15 & 41,7 & 0 & 0,0 & 21 & 58,3 & 0 & 0,0 & 0 & 0,0 & 36 & 100,0 \\
\hline Guaraí & 6 & 11,8 & 9 & 17,6 & 35 & 68,6 & 1 & 2,0 & 0 & 0,0 & 51 & 100,0 \\
\hline Gurupi & 0 & 0,0 & 0 & 0,0 & 19 & 48,7 & 20 & 51,3 & 0 & 0,0 & 39 & 100,0 \\
\hline Palmas & 6 & 11,1 & 1 & 1,9 & 18 & 33,3 & 29 & 53,7 & 0 & 0,0 & 54 & 100,0 \\
\hline Paraíso & 3 & 10,0 & 0 & 0,0 & 6 & 20,0 & 20 & 66,7 & 1 & 3,3 & 30 & 100,0 \\
\hline Porto Nacional & 3 & 8,3 & 0 & 0,0 & 7 & 19,4 & 26 & 72,2 & 0 & 0,0 & 36 & 100,0 \\
\hline Tocantinópolis & 32 & 59,3 & 0 & 0,0 & 22 & 40,7 & 0 & 0,0 & 0 & 0,0 & 54 & 100,0 \\
\hline Total & 199 & 38,6 & 12 & 2,3 & 163 & 31,6 & 139 & 26,9 & 3 & 0,6 & 516 & 100,0 \\
\hline
\end{tabular}

leve ou muito leve, seguida de Porto Nacional com 72,2\%, Paraíso do Tocantins 66,7\%, Palmas $53,7 \%$ e finalmente Gurupi com $51,3 \%$ das amostras com valores acima dos padrões no que diz respeito a quantidade preconizada pelos dois critérios de avaliação de fluoretos.

Na Tabela 4 é apresentado a melhor combinação risco/benefício, ou seja, a concentração ideal de fluoreto para que a população seja beneficiada com a proteção a cárie, sem correr o risco de desenvolver outro agravo, que seria a fluorose dentária. Percebe-se que 9 entre 10 municípios estão com suas análises fora do padrão ideal, ou seja, apenas $19,8 \%$ das amostras pesquisadas estavam com a melhor combinação, com o máximo benefício da prevenção à cárie dentária e o mínimo risco em produzir fluorose dentária. Unicamente a cidade de Guaraí possuiu a maioria das análises com melhor índice, $66,7 \%$ das amostras coletadas ideais, seguida por Dianópolis que apresentou $36,1 \%$, Tocantinópolis com $29,6 \%$ e Araguaína com $24,2 \%$ das amostras com porcentagem ideal. As demais cidades, que é a grande maioria, ou seja, $80,2 \%$ das amostras coletadas estão fora desta proporção ideal, todas abaixo de $10 \%$, sendo elas Paraiso com 6,7\%, Porto Nacional 5,6\%, Gurupi 5,1\%, Colinas e Palmas empatadas com $3,7 \%$ e finalizando com Araguatins que apresentou $0,0 \%$ das coletas ideais, todas com níveis de fluoretos bem próximos de nulo, o que caracteriza que a cidade de Araguatins não apresenta flúor natural e nem tampouco recebe o agregado.

Foram aplicados questionários à Vigilância ambiental estadual e ao Programa Vigiagua na tentativa de colher informações específicas sobre o sistema de vigilância da água e de fluoretação do Estado, como funcionamento, composição e ações executadas. O primeiro questionário foi aplicado durante a realização do projeto Vigiflúor multicêntrico no ano de 2014, projeto este que culminou nesta pesquisa, e o segundo foi aplicado em 2017, cujos resultados são apresentados no Quadro 1.

Quando a primeira etapa do projeto Vigiflúor multicêntrico foi iniciada em 2014 não era realizado o heterocontrole em nenhuma cidade do estado do Tocantins ${ }^{24}$, no que diz respeito a quantidade de fluoretos. Porém em Palmas, segundo a Secretaria Municipal de Saúde, o heterocontrole é realizado desde 2016. Observou-se também que, tanto a análise dos dados do Sisagua relativos a flúor, quanto a integração e ações com outros setores que também tenham interesse na qualidade da fluoretação, não eram realizadas em 2014, constatando que são executadas em 2017.

\section{Discussão}

Embora a política de fluoretação seja obrigatória e extremamente eficiente, o que se verificou é que a fluoretação das águas de abastecimento público ainda não é uma realidade tocantinense, e como agravante, ainda não dispõe de informações fidedignas para avaliar a extensão da cobertura dessa medida no estado, sendo a primeira vez que é realizado esse heterocontrole nas cidades do Tocantins. Torna-se mais evidente essa situação, 
Tabela 3. Frequências absolutas e relativas das classificações do risco em produzir fluorose dentária das amostras de água de abastecimento público segundo município. Tocantins, 2017.

\begin{tabular}{|c|c|c|c|c|c|c|c|c|c|c|c|c|}
\hline \multirow{3}{*}{ Município } & \multicolumn{12}{|c|}{ Risco } \\
\hline & \multicolumn{2}{|c|}{ Insignificante } & \multicolumn{2}{|c|}{ Baixo } & \multicolumn{2}{|c|}{ Moderado } & \multicolumn{2}{|c|}{ Alto } & \multicolumn{2}{|c|}{ Muito alto } & \multicolumn{2}{|c|}{ Total } \\
\hline & $\mathbf{N}$ & $\%$ & $\mathbf{N}$ & $\%$ & $\mathbf{N}$ & $\%$ & $\mathbf{N}$ & $\%$ & $\mathbf{N}$ & $\%$ & $\mathbf{N}$ & $\%$ \\
\hline Araguaína & 85 & 70,8 & 31 & 25,8 & 2 & 1,7 & 1 & 0,8 & 1 & 0,8 & 120 & 100,0 \\
\hline Araguatins & 42 & 100,0 & 0 & 0,0 & 0 & 0,0 & 0 & 0,0 & 0 & 0,0 & 42 & 100,0 \\
\hline Colinas & 7 & 13,0 & 2 & 3,7 & 2 & 3,7 & 42 & 77,8 & 1 & 1,9 & 54 & 100,0 \\
\hline Dianópolis & 15 & 41,7 & 13 & 36,1 & 8 & 22,2 & 0 & 0,0 & 0 & 0,0 & 36 & 100,0 \\
\hline Guaraí & 6 & 11,8 & 43 & 84,3 & 1 & 2,0 & 1 & 2,0 & 0 & 0,0 & 51 & 100,0 \\
\hline Gurupi & 0 & 0,0 & 2 & 5,1 & 17 & 43,6 & 20 & 51,3 & 0 & 0,0 & 39 & 100,0 \\
\hline Palmas & 6 & 11,1 & 3 & 5,6 & 16 & 29,6 & 29 & 53,7 & 0 & 0,0 & 54 & 100,0 \\
\hline Paraíso & 3 & 10,0 & 2 & 6,7 & 4 & 13,3 & 20 & 66,7 & 1 & 3,3 & 30 & 100,0 \\
\hline Porto Nacional & 3 & 8,3 & 2 & 5,6 & 5 & 13,9 & 26 & 72,2 & 0 & 0,0 & 36 & 100,0 \\
\hline Tocantinópolis & 32 & 59,3 & 16 & 29,6 & 6 & 11,1 & 0 & 0,0 & 0 & 0,0 & 54 & 100,0 \\
\hline Total & 199 & 38,6 & 114 & 22,1 & 61 & 11,8 & 139 & 26,9 & 3 & 0,6 & 516 & 100,0 \\
\hline
\end{tabular}

Tabela 4. Frequências absolutas e relativas da melhor combinação entre o máximo benefício da prevenção da cárie dentária e o mínimo risco em produzir fluorose dentária das amostras de água de abastecimento público segundo município. Tocantins, 2017.

\begin{tabular}{|c|c|c|c|c|c|c|}
\hline \multirow{3}{*}{ Município } & \multicolumn{6}{|c|}{ Melhor combinação entre benefício e risco } \\
\hline & \multicolumn{2}{|c|}{ Sim } & \multicolumn{2}{|c|}{ Não } & \multicolumn{2}{|c|}{ Total } \\
\hline & $\mathbf{N}$ & $\%$ & $\mathbf{N}$ & $\%$ & $\mathbf{N}$ & $\%$ \\
\hline Araguaína & 29 & 24,2 & 91 & 75,8 & 120 & 100,0 \\
\hline Araguatins & 0 & 0,0 & 42 & 100,0 & 42 & 100,0 \\
\hline Colinas & 2 & 3,7 & 52 & 96,3 & 54 & 100,0 \\
\hline Dianópolis & 13 & 36,1 & 23 & 63,9 & 36 & 100,0 \\
\hline Guaraí & 34 & 66,7 & 17 & 33,3 & 51 & 100,0 \\
\hline Gurupi & 2 & 5,1 & 37 & 94,9 & 39 & 100,0 \\
\hline Palmas & 2 & 3,7 & 52 & 96,3 & 54 & 100,0 \\
\hline Paraíso & 2 & 6,7 & 28 & 93,3 & 30 & 100,0 \\
\hline Porto Nacional & 2 & 5,6 & 34 & 94,4 & 36 & 100,0 \\
\hline Tocantinópolis & 16 & 29,6 & 38 & 70,4 & 54 & 100,0 \\
\hline Total & 102 & 19,8 & 414 & 80,2 & 516 & 100,0 \\
\hline
\end{tabular}

quando analisamos dados fornecidos pela companhia de abastecimento público do Tocantins informando que dos 139 municípios tocantinenses, apenas 29 possuem água fluoretada, resultando um montante de 110 municípios sem fluoretação.

Frazão et al. ${ }^{9}$ já haviam anunciado esta situação quando afirmaram que dos 139 municípios tocantinenses, apenas 5 informavam regularmente os sistemas do SISAGUA em 2013, demonstrando que os dados disponíveis eram insuficientes e parciais.
Vários autores têm demonstrado através de levantamentos epidemiológicos e pesquisas que a administração do flúor pós-eruptivo em dosagens constantes e seguras com a fluoretação da água de abastecimento público eficiente e confiável e dentro dos níveis ideais de fluoretos, irá propiciar um grande benefício e consequentemente diminuir de 30\% a 50\% o índice da cárie dentária na população ${ }^{18,25-29}$.

Unicamente a cidade de Guaraí possuiu a maioria das análises com melhor índice para maior proteção a cárie e menor risco a fluorose, 
Quadro 1. Comparativo entre dados fornecidos pelo Programa Vigiagua, em relação a qualidade da água do estado do Tocantins, em dois momentos distintos, 2014 e 2017.

\begin{tabular}{|c|c|c|}
\hline Perguntas realizadas & Ano $2014^{24}$ & Ano 2017 \\
\hline $\begin{array}{l}\text { O Estado realiza a vigilância da qualidade da água } \\
\text { pelo Vigiagua? Coordenado pelo MS? }\end{array}$ & Sim & Sim \\
\hline Composição técnica da equipe do Vigiagua & $\begin{array}{l}02 \text { biólogos, } \\
01 \text { engenheira de alimentos, } \\
01 \text { gestor ambiental }\end{array}$ & $\begin{array}{l}01 \text { biólogo, } \\
01 \text { engenheiro alimentos, } \\
02 \text { engenheiros ambientais }\end{array}$ \\
\hline Regionais envolvidas & 08 & 08 \\
\hline $\begin{array}{l}\text { Identificação, cadastramento, inspeção permanente, } \\
\text { monitoramento e acompanhamento do programa } \\
\text { da qualidade da água }\end{array}$ & Sim & Sim \\
\hline Análise dos dados do Sisagua relativos a flúor & Não & Sim \\
\hline $\begin{array}{l}\text { Realização de inquéritos e investigações relativas a } \\
\text { fluoretação }\end{array}$ & Não & Não \\
\hline $\begin{array}{l}\text { Integração e ações com outros setores que também } \\
\text { tenham interesse na qualidade da fluoretação. }\end{array}$ & Não & Sim \\
\hline $\begin{array}{l}\text { Controle operacional pelas companhias de } \\
\text { abastecimento }\end{array}$ & Sim. Relatórios mensais & $\begin{array}{l}\text { Sim. Relatório semanal e } \\
\text { diário }\end{array}$ \\
\hline Heterocontrole pelo Estado & Não & Não \\
\hline Heterocontrole pelos Municípios & Não & $\begin{array}{l}\text { Sim apenas em Palmas. } \\
\text { Relatório semanal. }\end{array}$ \\
\hline $\begin{array}{l}\text { Tipo de laboratório/método que realiza o } \\
\text { heterocontrole }\end{array}$ & Não realiza & $\begin{array}{l}\text { Laboratório próprio } \\
\text { LACEN }\end{array}$ \\
\hline $\begin{array}{l}\text { Existe legislação específica no Estado relativa a } \\
\text { fluoretação das águas de abastecimento público? }\end{array}$ & Não & Não \\
\hline
\end{tabular}

Fonte: Pinheiro et al. ${ }^{24}$.

com $66,7 \%$ das amostras coletadas ideais, porém ficando fora do primeiro parâmetro utilizado por essa pesquisa (Portaria GM/MS no 635/1975 ${ }^{8}$ ), uma vez que a média geral $(0,54 \mathrm{ppm})$ dos valores de flúor encontrado nas coletas desta cidade é abaixo do preconizado.

Dos 10 municípios pesquisados, apenas a capital Palmas manteve-se dentro dos dois parâmetros estabelecido por este estudo, ficando com uma média de fluoreto de 0,78 ppm, porém, $96,3 \%$ das amostras analisadas não apresentam melhor combinação entre o máximo benefício da prevenção da cárie dentária e o mínimo risco em produzir fluorose dentária, uma vez que uma grande parte das amostras analisadas estavam acima dos valores aceitáveis e outras com valores ideias, o que resultou uma média quase no limite máximo tolerado, aumentando o risco da população à fluorose dentária.

Os municípios de Araguaína, Araguatins, Tocantinópolis, Dianópolis e Guaraí estão abaixo dos valores recomendados pela portaria específica e pelo consenso técnico de flúor, estando estas cidades sem a cobertura contra a cárie dentária, porém, possuindo risco nulo a fluorose. Já os municípios de Colinas do Tocantins, Paraíso do
Tocantins e Porto Nacional estão com concentração de flúor acima do preconizado, levando em consideração os dois critérios. Neste caso, a população dessas 3 cidades, estão expostas a risco moderado e alto de desenvolver fluorose dentária leve ou muito leve, possuindo benefício máximo contra a cárie. Gurupi por sua vez, está dentro do $2^{\circ}$ critério, porém, está acima do $1^{\circ}$ padrão estabelecido, apresentando baixo risco ao desenvolvimento da fluorose dentária e máxima proteção contra a cárie dentária.

Para essa pesquisa foram escolhidos propositalmente dois parâmetros de avaliação, sendo o $1^{\circ}$ parâmetro as Portarias GM/MS no $635 / 1975^{8}$ e a MS 2.914/2011 $1^{30}$ que se complementam e são as legislações utilizadas pelos órgãos de fiscalização da água em todos os estados que não possuem uma portaria específica, classificando os valores de fluoretos até a temperatura máxima de $32,5^{\circ} \mathrm{C}$, o que se encaixa parcialmente na realidade do estado do Tocantins.

Por esse motivo foi acrescentado um $2^{\circ}$ parâmetro de avaliação, o Consenso Técnico sobre Fluoretos do CECOL em 2011, como sugestão para superar essa limitação das portarias antigas, tanto de valores como de formas de avaliar 
as consequências da aplicação do fluoreto, onde os pesquisadores recomendam que a avaliação do teor de flúor na água seja feita considerandose, simultaneamente, as dimensões relacionadas com o benefício e o risco, buscando-se aferir, em cada análise, as intensidades tanto do benefício preventivo da cárie dentária quanto do risco inerente à exposição a flúor (natural ou agregado).

Os valores dos dois critérios são bem semelhantes no que diz respeito a quantidade e média de fluoretos aceitável, mas são bastante diferentes no que diz respeito ao limite máximo permitido $\left(1^{\circ}\right.$ critério $=1,5 \mathrm{ppm}$ ou $\mathrm{mgF} / \mathrm{L} ; 2^{\circ}$ critério $=0,84 \mathrm{ppm}$ ou $\mathrm{mgF} / \mathrm{L})$. Entretanto, em todo o país, tendo em vista as médias de temperaturas máximas anuais, a concentração determinada para a prevenção máxima de cárie e limitação da ocorrência de fluorose do esmalte estão entre 0,6 e $0,8 \mathrm{mg} / \mathrm{L}^{1}$.

Os resultados desta pesquisa corroboram com vários outros estudos que, também têm alertado para a grande diversidade dos teores de flúor nas águas de abastecimento público. Isso reforça a necessidade de implantação de sistemas de vigilância, comprovando a relevância de um heterocontrole, que seja realizado de forma eficaz e contínua, para manutenção de padrões adequados a fim de assegurar a qualidade da fluoretação ${ }^{14,16-18,31-33}$.

Os valores ideais de fluoretos mudam de região para região, dependendo da média da temperatura local, baseado na ideia de que em temperaturas mais altas bebe-se mais água, portanto necessita-se de menos fluoretos. Uma vez que Alvares et al. ${ }^{34}$ constataram que a temperatura mínima do estado oscilaria entre $20^{\circ} \mathrm{C}$ e a máxima ficaria acima de $32^{\circ} \mathrm{C}$, chegando a $40^{\circ} \mathrm{C}$, demonstrando uma grande oscilação de temperatura média, justificando que os valores de fluoretos no estado do Tocantins não deveriam ultrapassar os valores de $0,84 \mathrm{mgF} / \mathrm{L}$ ou $\mathrm{ppm}^{23}$.

Frazão et al. ${ }^{4}$ concluíram na sua pesquisa que a ingestão diária de água com fluoreto em concentração $>0,9 \mathrm{mg} / \mathrm{L}$ representa risco à dentição em menores de oito anos de idade e segundo as evidências científicas, o risco é a possibilidade de ocorrer fluorose dentária, em diferentes graus, com predomínio dos graus "muito leve" e "leve", sendo assim, os consumidores deveriam ser expressamente informados desse risco. Neste sentido, considerando a expansão do programa nacional de fluoretação da água para regiões de clima tipicamente tropical, e as divergências entre informações e valores referentes ao uso do fluoreto em diferentes temperaturas, reforça-se a sugestão dos autores sobre a necessidade de revisão da Portaria GM/MS no 635/1975.

Os questionários aplicados demonstraram as mudanças ocorridas nestes três anos em relação a vigilância da água, percebendo-se uma evolução no quesito execução do heterocontrole, pois no primeiro questionário nenhuma cidade do estado realizava a medida, enquanto no segundo, a cidade de Palmas iniciou esta medida em 2016 e as demais cidades, conforme a Secretaria de Estado de Saúde, estão se organizando para realizarem esse controle adicional.

Vislumbra-se uma maior preocupação e cuidado da vigilância ambiental no que diz respeito a quantidade do íon fluoreto na água fornecida aos tocantinenses e a movimentação em equipar o laboratório de referência do estado e treinar técnicos para a realização do heterocontrole.

Outra mudança percebida pelos questionários foi a integração de ações com outros setores que também tenham interesse na qualidade da fluoretação, como a academia, tendo como exemplo real este projeto, que vem pesquisando a qualidade da fluoretação da água no Tocantins desde 2014 em parceria com a secretaria estadual de saúde do Tocantins, na tentativa de beneficiar a sociedade em geral e gerar mudanças nesta política pública de saúde eficaz e necessária a um estado com situação socioeconômica tão precária como este.

Constatou-se que ainda não existe uma legislação específica no Estado relacionada a fluoretação das águas de abastecimento público, sendo o Tocantins regulamentado pelas portarias nacionais, generalizadas e antigas, que não levam em consideração a peculiaridade do estado no que diz respeito ao clima, condições socioeconômicas e consumo individual de fluoretos. Sendo assim, percebeu-se a necessidade da criação de uma portaria estadual sobre uso de fluoretos na água de abastecimento público.

Segundo a companhia de abastecimento de água do Tocantins, falta de recursos financeiros e recursos humanos para a instalação dos reservatórios de fluoretos são obstáculos enfrentados para a execução de sistemas de fluoretação nas 110 cidades tocantinenses que ainda não possuem flúor na água de abastecimento público.

Frias et al. ${ }^{35}$ estimaram o custo da fluoretação das águas de abastecimento público. Para tal estudo, levaram em conta os custos com capital inicial de instalação; produto químico (ácido Fluossilícico); operacionalização do sistema (manutenção do sistema, energia elétrica e recursos humanos); e controle dos teores de flúor. Constataram que, 
o custo médio per capita/ano na Cidade de São Paulo foi de R \$ 0,08 (US\$ 0,03) em 2003. O custo acumulado em 18 anos de implantação do sistema de fluoretação foi de R $\$ 1,44$ (US\$ 0,97) per capita, indicando que estes custos eram tão pouco significativos comparativamente, que sua inclusão nos cálculos das tarifas não alterava o valor final para o consumidor, frente ao conjunto de despesas com tratamento de água, ressaltando a eficiência no custo benefício do flúor.

Além disso, constatou-se o desconhecimento parcial ou total das normativas e consensos técnicos atuais sobre fluoretação da água de abastecimento público, sendo observada a necessidade de realização contínua de treinamentos com os profissionais ligados a saúde, inclusive entre os profissionais ligados a potabilidade da água, tornando-se evidente a necessidade de se discutir mais o assunto entre profissionais de saúde em geral. Os mesmos resultados também foram encontrados por Ferreira et al. ${ }^{18,36}$ onde também foi verificado a falta de informações entre a população em geral e entre os gestores dos conselhos de saúde no que diz respeito a fluoretação da água.

Esta pesquisa teve como limitações o acesso ao sistema de informação municipal e estadual sobre a qualidade da água, além da dificuldade

\section{Colaboradores}

APAG Lacerda trabalhou na concepção, pesquisa, metodologia e redação final. NA Oliveira orientador do trabalho em todas as etapas. HHC Pinheiro coorientador do trabalho em todas as etapas. KML Assis trabalhou na articulação para coleta de dados, metodologia e redação final. JA Cury realizou as análises laboratoriais das amostras de água e revisou a redação final do manuscrito. de contato direto com os gestores dos municípios pesquisados e da impossibilidade de adentrar as Estações de tratamento de água (ETA) das cidades, sendo as coletas então realizadas em outros pontos estratégicos nos 10 municípios.

\section{Conclusão}

Conclui-se que $80,2 \%$ das amostras analisadas não estavam adequadas no que diz respeito a quantidade de fluoretos, onde 8 municípios possuem flúor agregado a água, porém, 9 em cada 10 amostras não estão no padrão adequado de menor risco a fluorose dentária e maior proteção contra a cárie dentária.

Ultima-se que não é realizado o heterocontrole no interior do estado do Tocantins, apenas na capital Palmas, e existe uma necessidade eminente de uma portaria estadual sobre Fluoretação, dentro dos preceitos locais.

Reiteramos também, a necessidade de maiores discussões com as autoridades locais, com a população em geral e instituições responsáveis pela potabilidade da água para se debater e evidenciar o assunto, sensibilizando-os para a importância do controle social.

\section{Agradecimentos}

Ao CNPq pelo financiamento do projeto Vigiflúor, e ao Coordenador do referido projeto, Dr. Paulo Frazão, Professor Titular da Faculdade de Saúde Pública da Universidade de São Paulo, pela condução do estudo multicêntrico prévio a este estudo. 


\section{Referências}

1. Brasil. Fundação Nacional de Saúde (Funasa). Manual de fluoretação da água para consumo humano. Brasília: Funasa; 2012.

2. Brasil. Ministério da Saúde (MS), Coordenação Nacional de Saúde Bucal. Guia de recomendações para o uso de fluoretos no Brasil. Brasília: MS; 2009.

3. Horowitz H. The 2001 CDC Recommendations for Using Fluoride to Prevent and Control Dental Caries in the United States. Journal of Public Health Dentistry 2003; 63(1):3-8.

4. Frazão P, Peres MA, Cury JA. Qualidade da água para consumo humano e concentração de fluoreto. Rev Saude Publica 2011; 45(5):964-973.

5. Antunes JLF, Narvai PC. Políticas de saúde bucal no Brasil e seu impacto sobre as desigualdades em saúde. Rev Saude Publica 2010; 44(2):360-365.

6. Brasil. Congresso Nacional. Lei 6.050, de 24 de maio de 1974. Dispõe sobre a fluoretação da água em sistemas de abastecimento quando existir estação de tratamento. Diário Oficial da União 1974; 27 maio.

7. Brasil. Decreto no 76.872 , de 22 de dezembro de 1975. Regulamenta a lei 6.050/74, que dispõe sobre a fluoretação da água em sistemas públicos de abastecimento. Diário Oficial da União 1975; 23 dez.

8. Brasil. Ministério da Saúde (MS). Portaria no 635, de 26 de dezembro de 1975. Aprova normas e padrões sobre fluoretação da água dos sistemas públicos de abastecimento, destinada ao consumo humano. Brasília: MS; 2011. Diário Oficial da União 1975; 26 dez.

9. Frazão P, Soares CCS, Fernandes GF, Marques RAA, Narvai PC. Fluoretação da água e insuficiências no sistema de informação da política de vigilância à saúde. Rev Assoc Paul Cir Dent. 2013; 67(2):94-100.

10. Narvai PC, Frias A C, Fratucci MVB, Antunes JLF, Carnut L, Frazão P. Fluoretação da água em capitais brasileiras no início do século XXI: a efetividade em questão. Saude Debate 2014; 38(102):562-571.

11. Petersen, P. The World Oral Health Report 2003: continuous improvement of oral health in the 21 st century - the approach of the WHO Global Oral Health Programme. Community Dentistry and Oral Epidemiology 2003; 31(Supl. 1):3-24.

12. Frazão P, Narvai PC. Fluoretação da água em cidades brasileiras na primeira década do século XXI. Rev Saude Publica 2017; 51:47.

13. Carvalho RB, Medeiros UV, Santos K, Santos KT, Pacheco Filho AC. Influência de diferentes concentrações de flúor na água em indicadores epidemiológicos de saúde/doença bucal. Cien Saude Colet 2011; 16(8):3509-3518.

14. Cangussu MCT, Narvai PC, Castellanos FR, Djehizian V. A fluorose dentária no Brasil: uma revisão crítica. Cad Saude Publica 2002; 18(1):7-15.

15. Santiago MR, Silva JLS. O flúor em águas subterrâneas: um problema social. In: Anais do XVIII Simpósio Brasileiro de Recursos Hídricos; Cuiabá; 2004.

16. Cesa K, Abegg C, Aerts D. A Vigilância da fluoretação de águas nas capitais brasileiras. Epidemiol Serv Saude 2011; 20(4):547-555.

17. Freitas CHSM, Sampaio FC, Roncalli AG, Moysés SJ. Reflexões metodológicas sobre prevalência da fluorose dentária nos inquéritos de saúde bucal. Rev Saude Publica 2013; 47(Supl. 3):138-147.
18. Ferreira RGLA, Marques RAA, Menezes LMB, Narvai PC. Múltiplos aspectos do uso do flúor em saúde pública na visão de lideranças da área de saúde. Cien Saude Colet 2013; 18(7):2139-2146.

19. Tocantins. Secretaria de Estado da Saúde, Superintendência de Vigilância e proteção à Saúde. Manual de coleta para análises de água de consumo humano. Palmas: Secretaria de Estado de Saúde; 2016.

20. Brasil. Ministério da Saúde (MS). Secretária de Vigilância em Saúde. Diretriz nacional do plano de amostragem de vigilância em saúde ambiental relacionada a qualidade da água para consumo humano. Brasilia: MS; 2006.

21. Ely HC, Frazão P, Faquim JPS, Neves M, Cesa K, Toassi RFC, Cury JA, Narvai PC. Guia de amostragem para vigilância da concentração do fluoreto na água de abastecimento público. In: Frazão P, Narvai PC, organizadores. Cobertura e vigilância da fluoretação da água no Brasil: municípios com mais de 50 mil habitantes. São Paulo: FSP-USP; 2017. p. 87-101.

22. Cury JA, Tabchoury COM, Tenuta LMA, Frazão P, Narvai PC. Protocolo de coleta e análise da amostra de água para o fluoreto. In: Frazão P, Narvai PC, organizadores. A Cobertura e vigilância da fluoretação da água no Brasil: municípios com mais de 50 mil habitantes. São Paulo: FSP-USP; 2017. p. 102-111.

23. Centro Colaborador do Ministério da Saúde em Vigilância da Saúde Bucal (CECOL/USP). Consenso técnico sobre classificação de águas de abastecimento público segundo o teor de flúor. São Paulo: Faculdade de Saúde Pública da Universidade de São Paulo; 2011.

24. Pinheiro HHC, Rebelo MABR, Vieira JMR, Castro VPHDF, Lacerda APAG, Souza MS, Cury JÁ, Narvai PC. Cobertura e vigilância da fluoretação das águas nos municípios com mais de 50 mil habitantes da região Norte. In: Frazão P, Narvai PC, organizadores. Cobertura e vigilância da fluoretação da água no Brasil: municípios com mais de 50 mil habitantes. São Paulo: FSP-USP; 2017. p. 113-130.

25. Narvai PC. Cárie dentária e flúor: uma relação do século XX. Cien Saude Colet 2000; 5(2):381-392.

26. Narvai PC, Castellanos RA, Frazão P. Prevalência de cárie em dentes permanentes de escolares do Município de São Paulo, SP, 1970-1996. Rev Saude Publica 2000; 34(2):196-200.

27. Cury JA. Uso de flúor e controle da cárie como doença. In: Baratieri LN, organizador. Odontologia Restauradora: fundamentos e possibilidades. São Paulo: Santos; 2001. p. 31-68.

28. Centers for Disease Control and Prevention (CDC). Achievements in Public Health, 1900-1999: fluoridation of drinking water to prevent dental caries. $M M W$ Morb Mortal Wkly Rep 1999; 48(41):933-940.

29. Ramires I, Buzalaf MAR. A fluoretação da água de abastecimento público e seus benefícios no controle da cárie dentária: cinqüenta anos no Brasil. Cien Saude Colet 2007; 12(4):1057-1065.

30. Brasil. Ministério da Saúde (MS). Portaria no 2.914, de 12 de dezembro de 2011. Dispõe sobre os procedimentos de controle de vigilância da qualidade da água para o consumo humano e seu padrão de potabilidade. Diário Oficial da União; 2011. 
31. Peixoto DF. Heterocontrole da Fluoretação da Água de Abastecimento Público no Município de Jaguarabiraba, Ceará, Brasil. Rev Bras Promo Saude 2012; 25(3):271-277.

32. Panizzi M, Peres MA. Dez anos de heterocontrole da fluoretação de águas em Chapecó, Estado de Santa Catarina, Brasil. Cad Saude Publica 2008; 24(9):20212031.

33. Ramires I, Maia LP, Rigolizzo DS, Lauris JRP, Buzalaf MAR. Heterocontrole da fluoretação da água de abastecimento público em Bauru, SP, Brasil. Rev Saude Publica 2006; 40(5):883-889.

34. Alvares CA, Stape JL, Sentelhas PC, Gonçalves JLM. Modeling monthly mean air temperature for Brazil. Theoretical Applied Climatology 2013; 113(3-4):407-427.

35. Frias AC, Narvai PC, Araújo ME, Zilbovicius C, Antunes JLF. Custo da fluoretação das águas de abastecimento público, estudo de caso Município de São Paulo, Brasil, período de 1985-2003. Cad Saúde Publica 2006; 22(6):1237-1246.

36. Ferreira RGLA, Bógus CM, Marques RAA, Menezes LMB, Narvai PC. Fluoretação das águas de abastecimento público no Brasil: o olhar de lideranças de saúde. Cad Saude Publica 2014; 30(9):1884-1890.

Artigo apresentado em 04/03/2018

Aprovado em 15/08/2018

Versão final apresentada em 17/08/2018 